\title{
IARPJe: Automação de processos no TRF1 para o Auxílio Emergencial
}

\section{IARPJe: Process automation at TRF1 for Emergency Aid}

\author{
Gleison Guardia ${ }^{1 *}$, Isarael Azevedo Fabiano ${ }^{2}$, Miguel Bonim do Nascimento ${ }^{3}$
}

\begin{abstract}
RESUMO
No Brasil, além das mortes incontroláveis, a COVID-19 mudou o jeito de convivermos e trabalharmos. Muitas pessoas perderam seus empregos, outras foram impedidas de trabalhar. Para mitigar estes impactos, o governo federal implantou o auxílio emergencial, consistindo-se de uma ajuda financeira para as pessoas mais carentes e ou que estivessem em vulnerabilidade social. Milhares de pessoas que não receberam o auxílio emergencial, recorreram à Justiça Federal solicitando seu direito, fato que ocasionou num grande acúmulo de processos num sistema que já está sobrecarregado. Com a finalidade de auxiliar o TRF1, a equipe do IARPJe foi convidada a implementar uma solução automatizada que solucionasse o problema. O robô implementado e desenvolvido em Python utilizando a metodologia de Web Scraping, movimentou e minutou mais de 23 mil processos que aguardavam sentença em 30 dias de funcionamento, mostrando-se eficaz e robusto para automação de tarefas no PJe.
\end{abstract}

Palavras-chave: COVID-19; Python; Web Scraping; PJe.

\section{ABSTRACT}

In Brazil, besides the uncontrollable deaths, COVID-19 changed the way we live and work. Many people lost their jobs, others were prevented from working. To mitigate these impacts, the federal government implemented emergency aid, consisting of financial aid for the neediest people and/or those in social vulnerability. Thousands of people who did not receive the emergency aid appealed to the Federal Court for their right, a fact that caused a great backlog of cases in a system that is already overloaded. In order to assist TRF1, the IARPJe team was invited to implement an automated solution to solve the problem. The robot implemented and developed in Python using the Web Scraping methodology, moved and minuted more than 23,000 processes that were awaiting sentencing in 30 days of operation, proving to be effective and robust for task automation in PJe.

Keywords: COVID-19; Python; Web Scraping; PJe.

\footnotetext{
${ }^{1}$ Instituto Federal de Educação, Ciência e Tecnologia de Rondônia.

*E-mail: gleison.guardia@ifro.edu.br

2 Tribunal Regional Federal da 1aㅡ Região

3 Grandal Sistemas
} 


\section{INTRODUÇÃO}

O ano de 2019 terminou com a notícia na China de uma infecção viral e desconhecida assemelhando-se a uma gripe. Com o passar dos dias, o mundo ficou chocado com o poder de infecção e letalidade, contagiando o planeta e fazendo a população mundial contar diariamente, horrorizados, os números crescentes de seus mortos.

O mês de março de 2020 foi o marco do enfrentamento ao conhecido vírus SARS-CoV2 da COVID-19, que neste momento já deixou mortos em quase todas as nações. Escolas fecharam, a circulação de pessoas começou a ser restringida, comércios foram obrigados a fechar suas portas, e o termo lockdown passou a ser comum em nossos dias.

Atualmente, janeiro de 2022, mais de dois anos após a descoberta do vírus, o mundo conta seus mortos e infectados. Abaixo é possível ver a tabela que traz os dados atualizados até a última revisão deste artigo:

Tabela 01: Situação da COVID-19 no mundo

\begin{tabular}{ccc}
\hline \multicolumn{3}{c}{ Números atualizados sobre a Pandemia do COVID-19 01/2021 } \\
\hline & Infectados & Óbitos \\
\hline Brasil & 23595178 & 622476 \\
\hdashline Global & 342595178 & 5574201 \\
\hline
\end{tabular}

Fonte: Gogle Notícias (2022. Pg 1)

Mesmos com esses números assustadores, a corrida para uma vacinação ampla e as disputas por insumos, o mundo vê atônito novas variante do vírus, ainda mais contagiosas se disseminando nos países, fazendo vítimas e trazendo desespero numa população (INSTITUTO BUTANTAN, 2021).

O fechamento programado e às vezes repentino dos comércios, indústrias e demais setores produtivos, trouxe uma grande perda de renda para as famílias mais carentes do Brasil, e por isso, como ação de mitigação dos efeitos, o Governo Federal agiu em apoio às classes impactadas.

A Lei 13.982/2020, de 02 de abril de 2020, disciplina o auxílio emergencial, criado como uma das medidas de combate aos reflexos da Covid-19. Em seu art. $2^{\circ}$, a referida lei delimita quem terá direito de receber tal benefício sendo que alguns dos requisitos obrigatórios são, por exemplo, não ter recebido, no ano de 2018, rendimentos tributáveis acima de R \$ 28.559,70 (art. $\left.2^{\circ}, \mathrm{V}\right)$ e que não tenha emprego formal ativo (art. $2^{\circ}$, II) (BRASIL, 2020)

Uma vez preenchidos todos os requisitos, o cidadão tem direito a receber um valor específico para que, assim, possa cumprir as medidas de enfrentamento à Covid-19 como o isolamento social.

A Caixa Econômica Federal foi eleita como agente financeiro para analisar e realizar os pagamentos do auxílio emergencial e até o mês de novembro de 2020 processou 109,2 milhões 
de cadastros. Destes 67,8 milhões foram procedentes e o cidadão recebeu o referido auxílio. Os números são exorbitantes tendo sido creditados 262,8 bilhões de reais.

Para analisar os dados do cidadão que requer auxílio emergencial é feito um cruzamento de banco de dados da União. Entre eles o banco de dados da Receita Federal para verificar se o cidadão recebeu no ano de 2018 rendimentos tributáveis acima de $\mathrm{R} \$ 28.559,70$, logo um erro em um banco de dados pode causar imenso prejuízo a uma pessoa que realmente precisa do auxílio para alimentar sua família.

Mesmo com o grande número de beneficiários que tiveram o reconhecimento de seu pedido na via administrativa, 42 milhões de pessoas tiveram seus pedidos negados, podendo assim procurar o Poder Judiciário para corrigir a injustiça (CAIXA, 2020).

Uma vez que o auxílio emergencial foi criado pela União e que o operador financeiro dele é a Caixa Econômica Federal, quem tem competência para analisar a causa é prioritariamente a Justiça Federal.

Assim, o cidadão que teve seu direito desrespeitado pode contratar um advogado, o qual reunirá todos os documentos necessários, ou pode procurar a Justiça Federal e ser atendido pelo serviço de atermação. Atermação, por sua vez, é um setor dentro da Justiça que ouvirá o cidadão e produzirá um documento escrito narrando os fatos. Este setor também solicita os documentos que o cidadão tem disponíveis para comprovar o que disse.

A partir desse ponto, inicia-se um processo judicial e o cidadão passa a ser parte autora no processo. Findo o qual o Magistrado analisará o direito e os fatos e decidirá se o autor teve ou não um direito lesado.

Entretanto, o intervalo entre o início do processo e o fim comumente é bem extenso no Judiciário brasileiro e nele ocorrem atos processuais importantes, dos quais destacamos: a) após a análise do termo inicial é feita a citação da parte requerida; b) citada, a parte requerida deverá juntar aos autos a contestação, peça na qual deve alegar todos os fatos impeditivos do direito do autor, e obviamente juntar as provas ao processo; c) após a juntada da contestação, entre diversas outros atos processuais, é possível que a ação seja julgada pelo Magistrado (BUENO, 2020).

No caso um autor que teve seu pedido negado com a justificativa de que recebeu no ano de 2018 rendimentos tributáveis acima de $\mathrm{R} \$ 28.559,70$ precisaria apenas e somente comprovar que não recebeu tais valores para que caracterize um caso de deferimento do auxílio emergencial na via judicial. Tal comprovação pode ser feita com a apresentação de carteira de trabalho com vínculo empregatício do ano de 2018 que tenha como salário valor menor. Por óbvio isso não garante que o autor não recebeu renda de outras fontes pagadoras, mas caberá à parte requerida, União, provar tal fato.

Ocorre que nas ações em que o autor busca valores para prover sua família é comum que seja requerida a antecipação dos efeitos da tutela, que se trata de uma decisão provisória, para que 
seja concedido o direito pleiteado até que seja exarada sentença nos autos, decidindo definitivamente sobre pleito.

Nesse cenário, é necessário juntar ao processo a causa que deu motivo ao indeferimento do pedido na via administrativa para que, assim, o Magistrado analise as provas juntadas aos autos e defira ou não a decisão de antecipação de tutela. Não tendo sido juntado o motivo do indeferimento pela parte autora, o Magistrado determina a intimação da parte requerida para que esclareça tal motivo. Na prática, este ato processual pode levar até 17 dias e, por vezes, não ser atendido pela Procuradoria Federal devido ao grande volume de demandas, conforme já mencionado.

Sem as devidas informações nos autos o Magistrado pode deferir a antecipação da tutela e posteriormente a Procuradoria Federal demonstrar que existiam outros motivos que causaram o indeferimento na via administrativa. Por outro lado, caso o Magistrado decida pela não antecipação de tutela a parte autora poderá amargar o dissabor de ver faltar o alimento em sua mesa por uma injustiça cometida pelo Poder Executivo corroborada pelo Poder Judiciário.

No caso das ações que tenham como objeto o auxílio emergencial, não tendo a parte autora instruído o feito com a informação do motivo do indeferimento na via administrativa, duas são as opções para que esta informação seja trazida aos autos: a) intimar a parte requerida (União) para que informe o motivo do indeferimento ou b) um servidor que tenha acesso ao sistema da Dataprev deve acessá-lo, consultar essa informação e juntar aos autos por meio de uma certidão.

A primeira opção levará no mínimo alguns dias para se concretizar sendo que o prazo máximo, incluindo prazos legais e do sistema PJe, será de 17 dias, conforme mencionado acima.

A segunda opção é muito mais ágil, mas exige que o poder Judiciário junte aos autos uma prova, algo temerário e possível apenas com base no princípio da informalidade (um dos princípios que regem os Juizados Especiais Federais). Entretanto, no fim de 2020 havia, apenas no Tribunal Regional Federal da $1^{\text {a }}$ Região (TRF1) 27.093 ações que exigiriam esse procedimento que somados resultam em mais de 2.000 horas de trabalho dos servidores.

O sistema no qual essas ações tramitam é o PJe (Processo Judicial Eletrônico), um dos diversos sistemas que o TRF1 dispõe para seus servidores. Destacando-se pela sua abrangência e de uso obrigatório desde janeiro de 2019 , realiza a tramitação processual dos autos de forma totalmente digital.

Esse sistema é dividido em caixas e cada qual realiza uma determinada tarefa. A exemplo, um processo que acaba de ser distribuído encontra-se na caixa "Triagem inicial” e caso, após realizar a análise, o servidor necessite incluir uma certidão nos autos deve selecionar o processo, clicar no ícone "Encaminhar para..." e em seguida escolher a caixa "Minutar certidão". Apenas estando na referida caixa de destino é que será possível acessar o editor de texto, próprio do sistema, e então selecionar o modelo ou digitar toda a certidão. Após a edição do texto o processo 
pode ser encaminhado para a caixa "Assinar certidão". Abaixo temos a figura 01 que nos dimensiona a organização do PJe.

Figura 01: Print do painel de usuário do Pje

\begin{tabular}{|c|c|}
\hline \multicolumn{2}{|l|}{ D Tarefas } \\
\hline Filtros & - \\
\hline [JEF] Escolher tipo de requisição de pagamento & 100 \\
\hline [JEF] Minutar Decisão - Gabinete & 209 \\
\hline [JEF] Minutar Decisão - Secretaria & 3 \\
\hline [JEF] Minutar Despacho - Gabinete & 14 \\
\hline [JEF] Minutar Despacho - Secretaria & 7 \\
\hline [JEF] Minutar Sentença - Gabinete & 185 \\
\hline [JEF] Minutar ato ordinatório & 113 \\
\hline [JEF] Minutar certidão & 1 \\
\hline [JEF] Preparar RPV & 15 \\
\hline [JEF] Preparar comunicações - rotina individual & 3 \\
\hline [JEF] Preparar precatório & 2 \\
\hline [JEF] Recebidos da rotina de comunicações e outros expedientes & 43 \\
\hline [JEF] Revisar Sentença - Gabinete & 3 \\
\hline [JEF] Sobrestados para aguardar julgamento de outra causa ou recurso & 3 \\
\hline [JEF] Sobrestados por outros motivos & 66 \\
\hline [JEF] Tramitação MP-Policia & 1 \\
\hline [JEF] Triagem inicial URGENTES & 2 \\
\hline [JEF] Triagem inicial & 9 \\
\hline [Migração OJ] Processos em migração & 4 \\
\hline
\end{tabular}

Fonte: GUARDIA, FABIANO e BONIM (2022, p.1)

A imagem acima apresenta o printscreen das tarefas disponíveis no painel do usuário do PJe. Do lado esquerdo as caixas e do lado direito a quantidade de processos dentro das caixas.

Apesar de proporcionar um considerável aumento na celeridade de tramitação de processos, o PJe não tem um módulo de automação disponível para o servidor utilizar. Dessa forma, sempre será necessário abrir os autos, ler os documentos e transitar de caixa em caixa até que seja concluída a tarefa necessária.

\section{AUTOMAÇÃO NO PJE}

O conceito de automação consiste em controlar os mecanismos para seu próprio funcionamento, ou seja, utiliza de técnicas computadorizadas ou mecânicas focando na otimização de tempo, redução de custos e prezando pela qualidade do serviço produzido (ADMIN, 2017). 
Alguns processos no âmbito de trabalho contêm tarefas repetitivas que podem ser automatizadas, retirando-se o agente humano e abrindo portas para softwares realizarem o trabalho (RIBEIRO, 2016).

Alguns benefícios em aplicar um sistema automatizado são:

- Aumento de produtividade: este é um dos benefícios mais buscados por quem almeja utilizar um sistema automatizado. Como a automação empregada permite o alcance de ciclos de produção céleres e mais eficazes, expondo que um trabalhador não teria a capacidade de realizar o mesmo trabalho em menos tempo, sendo necessário várias pessoas para desenvolver a mesma atividade, é evidente que a produtividade mais que duplica com um sistema automatizado.

- Redução de custos: como dito anteriormente, seria necessário mais de um agente humano para realizar as tarefas em mesma quantidade que um sistema automatizado, neste processo há uma redução de custos em aplicá-la. Considerando um custo inicial elevado, pois o investimento será pago com a própria produção, logo o lucro será satisfatório. Sendo um ponto essencial mencionar que com esses sistemas, alguns custos mensais fixos também podem diminuir, um exemplo seria o custo de energia elétrica, já que o sistema é extremamente ágil nas tarefas realizadas.

- Qualidade: a taxa de erro de uma máquina é significativamente mais baixa quando comparada com a do ser humano (ADMIN, 2017).

Para a automação de processos, a linguagem de programação Python é amplamente utilizada devido à sua robustez. Essa linguagem surgiu em 1989 e foi desenvolvida por Guido van Rossum no Centro de Matemática e Tecnologia da Informação (CWI, Centrum Wiskunde e Informática), na Holanda (DOWNEY, 2016).

Python é uma linguagem de programação orientada a objetos clara e poderosa, que desfruta de uma sintaxe elegante, no qual facilita a leitura dos programas escritos, tornando assim uma linguagem ideal para o desenvolvimento de protótipos, automação, inteligência artificial entre outros. Sendo uma linguagem livre é considerada de altíssimo nível (VHLL), além de desenvolver em tipagem dinâmica e multiplataforma (FLORENZANO, 2019).

Python permite utilizar módulos feitos em linguagens baixo-nível e de alta performance em um ambiente de alto nível e muito mais amigável conciliando performance e praticidade.

Outra atividade muito importante para o projeto foi a Web Scraping, termo dado para extração de dados relevantes de um determinado site da web para serem analisadas ou utilizadas posteriormente. É possível realizar esse processo manualmente salvando o código da página ou através de um algoritmo para automatizar essa extração. Esse conceito é bastante útil para economizar tempo e esforço, consistindo na junção de técnicas de programação e de tecnologias, aliadas à análise de dados, segurança da informação e parsing de idiomas naturais com a finalidade de automatizar processos (MITCHELL, 2019). 
Utilizando a linguagem Python para essa finalidade, temos o BeautifulSoup, biblioteca que possui este nome em referência a um poema de Lewis Carroll no livro Alice no país das maravilhas. Tanto lá como aqui, ele tem a finalidade de dar sentido ao que não tem sentido, ajudando a formatar e organizar a web confusa, formatando códigos HTML mal estruturados e entregando arquivos python em XML, fornecendo maneiras de pesquisar e modificar a árvore de análise. Dessa forma, ela é capaz de suportar as demandas de um sistema de automação devido a sua facilidade em analisar todas as informações (MITCHELL, 2019).

Após se extrair uma informação é necessário armazená-la em algum lugar para uso futuro ou registro de atividades, neste contexto o uso de banco de dados torna a atividade mais prática e robusta.

Banco de dados é a estrutura utilizada para armazenar dados que precisam ser recuperados posteriormente por algum motivo ou necessidade específica. Por exemplo, quando é preciso armazenar um cadastro de clientes ou até mesmo uma agenda telefônica, pode-se utilizar um caderno ou uma agenda em papel, fazendo as vezes do banco de dados. Assim, um banco de dados é um agrupamento de informações que estão relacionadas entre si em um mesmo local (BEAULIEU, 2010).

O SQLite, desenvolvido por D. Richard Hipp, é um sistema gerenciador de banco de dados relacional simples e eficiente ideal para soluções pequenas como: aplicativos desktop ou mobile, pequenos WebSites, sistemas utilizados por poucas pessoas. Por ser simples e pequeno, não é necessário a instalação e não precisa de um hardware poderoso para utilizá-lo (SQLITE, 2021).

Neste contexto apresenta-se o IARPJe, idealizado pela parceria IFRO e $1^{\mathrm{a}}$ Vara da Subseção Judiciária de Ji-Paraná, órgão pertencente à estrutura organizacional do TRF1. O IARPJe se constitui pelo desenvolvimento de automações e soluções de inteligência artificial que promovam a triagem de processos e as suas respectivas movimentações na plataforma do PJe.

O trabalho dentro de uma Vara Federal é bastante extenuante e repetitivo. Grande parte da carga horária dos servidores compromete-se à abertura de processos, identificação e classificação quanto ao tempo de urgência e ao tipo de tramitação. Dispor de um sistema autônomo que possa executar essas análises, possibilitará o aproveitamento do tempo dos servidores para dar seguimento aos processos, diminuindo consideravelmente a morosidade de sua tramitação.

O IARPJe é uma aplicação desenvolvida em linguagem de programação Python, promovendo automação das atividades e provisionar os gestores processuais de mecanismos formatados para, a um só tempo: a) reduzir a carga de atividade mecânica e repetitiva do servidor na mesma proporção que confere máxima efetividade ao trabalho já realizado; b) reduzir os riscos de falhas de triagem e de movimentação em processos, os quais são potencializados na medida 
do volume dos processos tratados na tarefa; c) implementar sistema que provê aumento significativo da agilidade na tramitação processual.

A automação de processos tem se mostrado necessária devido ao grande volume de trabalho e informações que inundam os meios digitais. Com a instrução e educação da população brasileira, cada vez mais o cidadão consciente e crítico busca nas esferas judiciais direitos e liberdades sufragadas de si.

O aumento inversamente proporcional do número de processos em relação ao número de servidores acaba gerando no Brasil, assim como no mundo, uma demanda por auxílio na condução, classificação e tramitação dos mesmos.

\section{IARPJe E AUXÍLIO EMERGENCIAL}

A par do desenvolvimento da solução IARPJe, a equipe de desenvolvimento autora deste artigo foi procurada por alguns magistrados com a finalidade de inserir de forma automática as informações constantes no relatório “Auxílio Emergencial com Análise da União” resultante de uma parceria entre o Conselho Nacional de Justiça (CNJ) e a Dataprev.

O relatório podia ser acessado por servidores do TRF1 pelo sistema E-Siest e reunia informações sobre os autos como: nome e CPF da parte autora, unidade judiciária responsável pelo processamento do feito, número do processo em tramitação e sua situação (se julgado ou não). Caso o benefício tivesse sido indeferido na via administrativa, o relatório traria o motivo do indeferimento e caso deferido, onde foi deferido, na via administrativa ou na via judicial e as situações das parcelas do benefício (podendo ser depositada, cancelada, entre outros). À época o relatório já contava com mais de 38 mil registros de processos judiciais dos quais 11 mil já haviam sido julgados, logo 27 mil processos eram passíveis de inclusão de certidão e a certificação manual seria impossível de ser realizada de forma centralizada por falta de mão de obra disponível.

Ocorre que o TRF1 é o maior Tribunal Federal em extensão territorial e em volume de processos, abrangendo 13 estados e o Distrito Federal conforme a figura 02 apresenta:

\section{Figura 02: Mapa do TRF1}

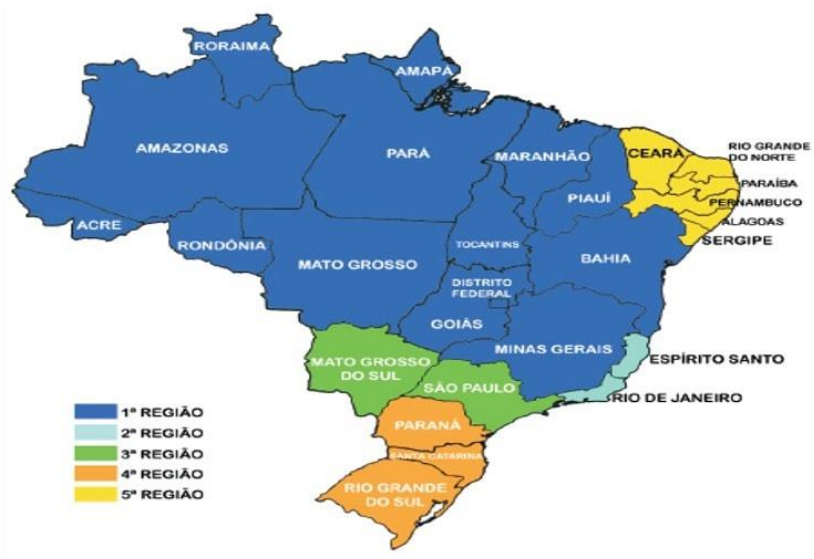

Fonte: KANASHIRO (2020, pg. 1) 
Após uma série de reuniões com a administração do Tribunal e com a Secretaria de Informação, foi decidido que a automação deveria ser executada por um único usuário já que se trata de uma automação em desenvolvimento e assim seriam necessários ajustes para correção de pequenas falhas que interrompiam a execução da automação.

Neste momento, a automação levava 60 segundos, em média, para certificar cada processo o que, apesar de ser um tempo muito inferior ao que um servidor humano levaria para realizar a tarefa, ainda caracterizava um problema, pois seriam necessários 24 dias de execução ininterrupta para cumprir a demanda excluídos os processos que surgissem no período. Além disso, o usuário que executasse a automação deveria ter acesso a todos os processos do relatório e conhecer o suficiente de programação para identificar e corrigir as falhas da automação). Ocorre que o servidor envolvido no desenvolvimento da solução o (IARPJe), tinha acesso apenas aos autos da $1^{\text {a }}$ Vara de Ji-Paraná e os servidores que tinham acesso a todos os autos do relatório não tinham experiência suficiente na linguagem de programação Python na qual a solução foi desenvolvida.

Como solução dos problemas acima apresentados, ficou decidido conceder acesso aos processos para o servidor envolvido no desenvolvimento da solução e garantido apoio da Secretaria de Tecnologia da Informação (Secin) e do Núcleo Regional de Apoio do Processo Judicial Eletrônico (Nupje).

Foi determinado, ainda, que as certidões fossem assinadas com o certificado digital do PJe. Isso significa que não mais apareceria como signatário o servidor que executa o script e sim a assinatura "Usuário do sistema" e que não seria mais necessária a espera do envio da assinatura da máquina que executa o script para a máquina que provê o PJe a qual fica na sede do tribunal em Brasília. Vale lembrar que o código estava sendo executado no interior de Rondônia e por mais que o envio da assinatura e recebimento da confirmação demorasse apenas alguns segundos, multiplicados por 27 mil significaria uma enorme quantidade de tempo que foi poupado com essa simples decisão.

Por parte da equipe de desenvolvimento, devido ao imenso número de processos e ao tempo que levaria para executar toda a tarefa, até então algo em torno de 20 dias, foi decidido utilizar SGBD SQLite como banco de dados a fim de controlar quais processos já haviam sido certificados e qual o estado do processo no ato da certificação, já que o relatório seria atualizado semanalmente e a situação do pedido na esfera administrativa poderia ser modificada.

Antes que acontecesse a assinatura do ato normativo que autorizasse a execução do código em todo o TRF1, foram certificados os processos cujo o Magistrado responsável autorizou, assim foram certificados 600 processos em algumas Varas Federais, em especial as Varas da Seção do Amapá. Nessa etapa foram identificados os erros mais comuns e resolvidos, conforme eram compreendidos. 
Também nessa etapa o tempo de execução de cada certificação caiu para cerca de 27 segundos graças aos vários ajustes feitos no código e no PJe. No Pje foi criado um fluxo paralelo no qual o processo era duplicado dentro da caixa "Minutar certidão" já com uma sinalização (etiqueta) que indicava para o servidor responsável pelos autos (processo judicial) que foi incluída uma certidão automatizada, o que economizou vários segundos na execução de cada tarefa.

A partir da assinatura da Portaria Conjunta PRESI/COGER/COJEF/SISTCON 11724920, o que ocorreu no dia 19/11/2020, foi iniciada a execução em massa e concomitantemente corrigidos bugs na execução do código.

A certificação funciona em quatro etapas: a) leitura do relatório e inserção das informações no banco de dados; b) inserção do processo em fluxo paralelo; c) inclusão da certidão automatizada e d) Registro no banco de dados da automação. Vejamos os passos a seguir:

A. O relatório em formato .csv era aberto pela biblioteca OS - Miscellaneous operating system, a interfaces e seus dados são lidos pela biblioteca padrão $c s v$, tratados pela biblioteca Pandas e os dados armazenados no banco de dados, desenvolvido em SQLite. Importante frisar que esta é a etapa de mais rápida execução e por isso foi decidido que os processos que já tivessem sentença não deveriam sequer entrar no banco de dados. Isso porque tendo a disputa já sido resolvida não era mais necessária a juntada de qualquer informação constante no relatório.

B. Conforme mencionado, o sistema PJe baseia-se em diversas caixas. Os processos poderiam estar em quaisquer delas, mas para que fosse possível inserir a certidão, o processo deveria estar na caixa "Minutar certidão".

Assim, a forma mais rápida e simples encontrada foi inserir o processo em fluxo paralelo que consiste em duplicar o processo sendo a cópia criada é inserida dentro da caixa correta e com a etiqueta "Certidão automatizada inserida".

Isso era feito pelo robô da mesma forma que o passo "c", explicado adiante, com alguns simples comandos de digitação e cliques (ver figura 03) e, após, registrado no banco de dados que o processo havia sido duplicado.

Figura 03: Página do PJe

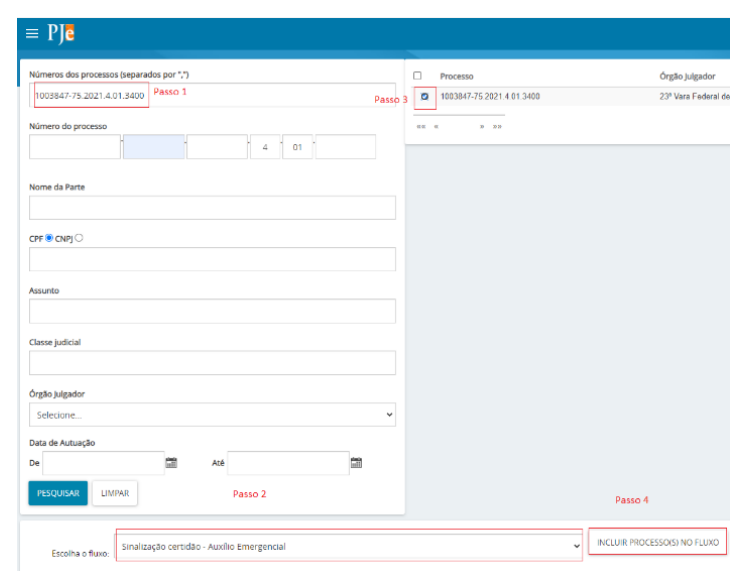

Fonte: GUARDIA, FABIANO e BONIM (2022, p.1) 
Passo 1: o número do processo é digitado no campo específico e enviado a tecla "enter".

Passo 2: enquanto o sistema processa a pesquisa o robô seleciona o fluxo desejado.

Passo 3: clique na caixa de seleção do processo pesquisado.

Passo 4: Clique no botão que inclui o processo no fluxo desejado, assim duplicando.

C. A inclusão da certidão nos autos, certamente, é a parte mais trabalhosa. Já que depende da interface do usuário final do sistema PJe, assim como o passo anterior, o robô deve estar preparado para todos os erros possíveis, erros que são comuns de acontecer, uma vez que o PJe está em desenvolvimento e sofre várias atualizações semanais que, quando implementam nova funcionalidade, podem criar novos erros.

Primeiramente, nesta etapa, acessa-se a caixa "Minutar certidão", na sequência é feita uma pesquisa no banco de dados e procura-se recuperar algum processo que esteja duplicado. Com o número de um processo em mãos, gera-se o texto da minuta; após, o robô pesquisa pelo número do processo, localiza e clica no processo, aguarda o carregamento do editor de texto. Uma vez carregado o editor, é necessário escolher o modelo padrão e inserir o texto já criado. A figura 04 abaixo apresenta o modelo base na caixa 'minutar certidão' com processo selecionado e editor de texto disponível para o usuário:

Figura 04: Página do PJe

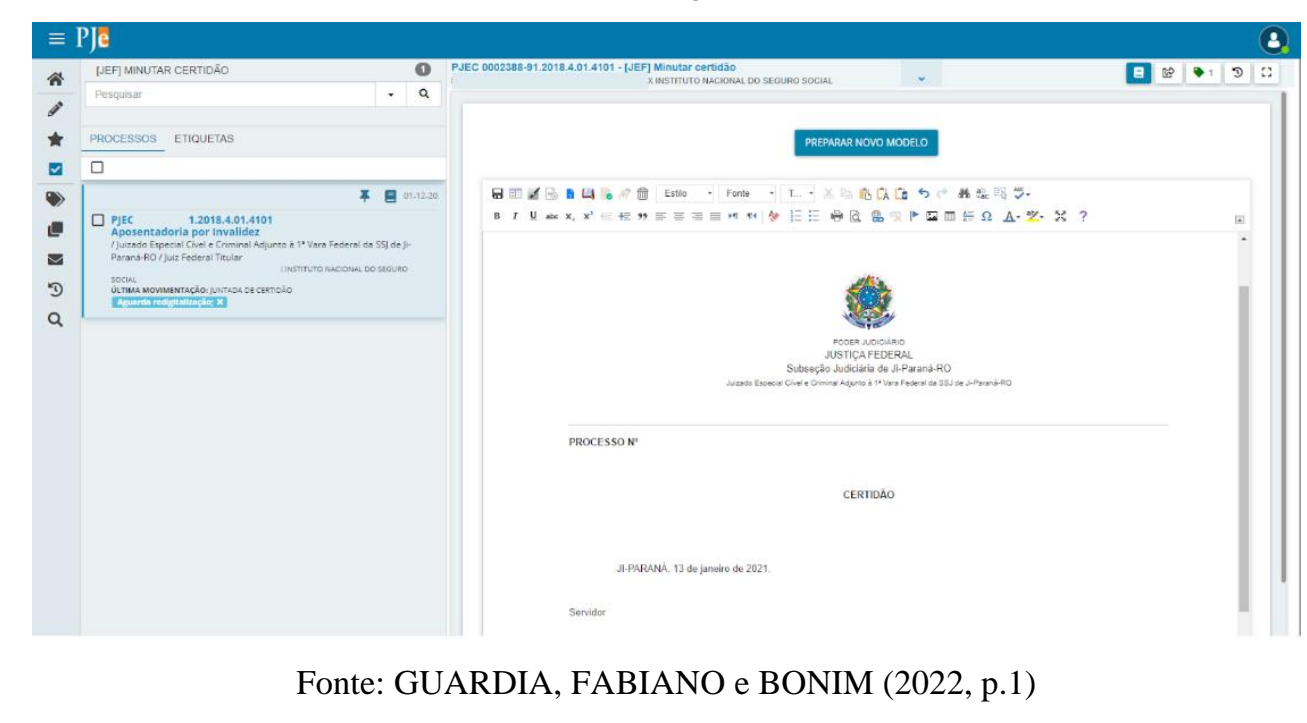

O processo de seleção de modelo, entretanto, era o que ocasionava o maior número de erros, logo foi solicitado ao Nupje que, ao ser duplicado, o processo já surgisse com um modelo escolhido. Essa modificação mostrou-se extremamente vantajosa tornando possível a execução de uma certificação em apenas 12 segundos além de aumentar a robustez do robô. Ademais a solução foi implementada em apenas 1 dia. 
O código, antes da modificação mencionada, certificava em média, 400 processos sem encontrar erros e suspender a execução. Após a modificação, essa média subiu para mais de 1.000 processos, tendo atingido por várias vezes mais de 2.000 certificações sem suspender a execução.

Para essas atividades foram utilizadas as bibliotecas Selenium e Beautifulsoup4. Selenium para navegação, captura de dados e envio de textos e Beautifulsoup4 quando necessário para melhorar o tempo de execução da captura dos dados.

D. O banco de dados era responsável exatamente por armazenar as informações referentes aos processos e as certidões inseridas, para controle posterior.

No fim de 2020 havia mais de 38 mil ações com o assunto auxílio emergencial e com todo o trabalho de equipe, envolvendo-se a equipe de desenvolvimento e a equipe do tribunal, no dia 07/12/2020, às 15:45, foi entregue relatório de atividades no qual constavam: 23.662 processos certificados, 744 processos não certificados por complexidades jurídicas, 12.862 processos não certificados, pois já tinham sentença e 71 processos que exigiam correção por inconsistência do sistema PJe. Tendo o tempo médio de execução nos últimos dias variado entre 12,3 e 14,5 segundos por certidão.

\section{CONCLUSÃO}

É inegável a importância que foi e ainda é a implantação do auxílio emergencial para uma parte significativa da população brasileira. Nestes momentos críticos e decisivos, a intervenção do Estado como fonte de resgate das necessidades do cidadão é fundamental e somente ele é capaz de tal abrangência e poder econômico.

Compreende-se também que mesmo implementando os programas, quando a urgência é gritante, os gargalos brasileiros de falta de pessoal, morosidade do trânsito jurídico e o tamanho continental do país, pode proporcionar atrasos e dificuldades na celeridade das atividades necessárias.

Entende-se que o avanço tecnológico é o grande propulsor para dirimir parte desta problemática, proporcionando ações rápidas e mecânicas com a automação capazes de suprir grande parte da mão de obra repetitiva permitindo ao país desenvolver seus servidores para o restrito da atividade intelectual e decisória.

Frente a todas essas adversidades e caminhos propostos, entende-se que a rápida evolução e execução da automação das minutas para os processos judiciais de auxílio emergencial, permitiu que incontáveis horas de serviço da justiça federal brasileira fossem cumpridos em um prazo impossível para os servidores do tribunal.

A automação do IARPJe para automatizar os processos dentro do PJe, com uso de Web Scraping, foi inegavelmente o diferencial neste final de ano tumultuado e conturbado para todos 
os brasileiros, e para a parte diretamente ligada aos processos movimentados, a garantia de dignidade, alimento na mesa e um alento no meio deste turbilhão chamado COVID-19.

Não é uma atividade onde os autores e os mais de 30 mil beneficiados se sentaram juntos para produzir uma solução. Este é um trabalho de uma pequena equipe, do interior de Rondônia, que mesmo desconhecida teve a certeza que pode contribuir com a nação brasileira, tendo como noção de dignidade e dever cumprido, possibilitando um final de ano mais social aos anônimos beneficiários.

\section{REFERÊNCIAS}

GOOGLE NOTÍCIAS. CORONAVÍRUS (COVID-19), 2021. Disponível em: $<$ https://news.google.com/covid19/map?hl=pt-BR\&gl=BR\&ceid=BR\%3Apt419\&mid=\%2Fm\%2F015fr > . Acesso em: 21 de janeiro de 2022 .

INSTITUTO BUTANTAN, Conheça os sintomas mais comuns da ômicron e de outras variantes da Covid-19. 2021. Disponível em <https://butantan.gov.br/noticias /conheca-os-sintomas-mais-comuns-da-omicron-e-de-outras-variantes-da-covid-19>, Acesso em: 21 de janeiro de 2022.

BRASIL. Lei 13.982, de 02 de Abril de 2020. Presidência da República. 2020, Disponível em <http://www.planalto.gov.br/ccivil_03/_ato20192022/2020/lei/113982.htm >. Acesso em: 10, janeiro, 2021.

CAIXA. Auxílio Emergencial: Clique aqui para saber os últimos números. Caixa Econômica Federal. 2020. Disponível em:

$<$ https://caixanoticias.caixa.gov.br/noticia/22125/auxilio-emergencial-clique-aqui-paraver-os-ultimos-numeros-2 >. Acesso em: 10, janeiro, 2021.

BUENO, Cassio Scarpinella e NETO, Olavo de Oliveira. Enciclopédia Jurídica da PUCSP: Processo Civil. PUC-SP. 2020. Disponível em:

$<$ https://enciclopediajuridica.pucsp.br/tomo/3 >. Acesso em: 12, janeiro, 2021.

ADMIN (ed.). O que é um sistema automatizado?. Blog da Automação Industrial. 2017. Disponível em: http://tectrolnet.com.br/blog/o-que-e-um-sistema-automatizado/. Acesso em: 30, março, 2020.

RIBEIRO, Marcus. Automação de processos sem complicação. Pluga. 2016. Disponível em: https://pluga.co/blog/gestao-empresarial/automacao-de-processos/. Acesso em: 30, março, 2020.

DOWNEY, Allen. B. Pense em Python: Pense como um cientista da computação. Tradução: Sheila Gomes. São Paulo: Novatec Editora, 2016.

FLORENZANO, Cláudio. Por que o Python é considerado a melhor linguagem de programação. 2019. disponível em: <https://www.cbsi.net.br/2019/11/por-que-opython-e-considerado-melhor.html> acesso em: 02 abril de 2020. 
MITCHELL, Ryan. Web Scraping como Python: Coletando mais dados na web moderna. Tradução: Lucia A. Kinoshita. 2a ed. São Paulo: Novatec Editora, 2019.

BEAULIEU, Alan. Aprendendo SQL. Tradução: Edgard Batista Domini. São Paulo: Novatec Editora, 2010.

SQLITE, ABOUT SQLITE. 2021. Disponível em: <https://www.sqlite.org/about.html >. Acesso em: 25, janeiro, 2021

KANASHIRO. Mapa de Competência do TRF1. Portal do Professor Kanashiro. 2020. Disponível em: <https://portalprofessorkanashiro.com.br/curso-tecnico-administrativotrf-1-a-regiao/mapa-competencia-trf-1-concurso-trf-1-regiao-professor-kanashiro/ > . Acesso em: 21 de janeiro de 2022.

Recebido em: 15/01/2022

Aprovado em: 05/02/2022

Publicado em: 10/02/2022 